\title{
CASE REPORT \\ Epidural haematoma following anticoagulant treatment in a patient with an indwelling epidural catheter
}

\author{
R. W. H. Skilton ${ }^{1}$ and W. Justice ${ }^{2}$ \\ 1 Visiting Instructor, and 2 Resident in Anaesthesia, Department of Anaesthesiology, University of Michigan Medical \\ Center, 1500 East Medical Center Drive, 1 G323 UH, Ann Arbor, MI 48109-0048, USA
}

\begin{abstract}
Summary
We report the occurrence of an epidural haematoma after the removal of a lumbar epidural catheter, which had been inserted 2 days previously for surgery to revise a thrombosed femoralpopliteal graft. Pre-operatively the patient received intravenous heparin by infusion, but this was stopped $7 \mathrm{~h}$ prior to epidural insertion. Coagulation studies were normal. The epidural catheter insertion was unremarkable. Postoperatively, the patient received a continuous epidural infusion of fentanyl $\left(3 \mu \mathrm{g} \cdot \mathrm{ml}^{-1}\right)$ and bupivacaine $(0.0625 \%)$, in addition to systemic anticoagulant therapy with heparin. On the second postoperative day, the patient was noted to have developed bilateral leg weakness (following transfer to another department for Doppler studies). The epidural catheter was inadvertently removed while the patient was anticoagulated and paraparesis developed overnight. After a significant delay, an epidural haematoma was diagnosed and treated by decompressive laminectomy. At operation an epidural haematoma extending posteriorly from $\mathrm{T}_{12}$ to $\mathrm{L}_{3}$ was removed.
\end{abstract}

Keywords Anaesthetic techniques, regional; epidural. Surgery; vascular. Complications; epidural haematoma.

Correspondence to: $\operatorname{Dr}$ R. W. H. Skilton

Accepted: 12 February 1998

Spinal bleeding resulting in permanent paraplegia is a 'worst case' scenario following epidural catheter insertion. Although the incidence of epidural bleeding may be as high as $10 \%$ following catheter placement, the incidence of significant spinal bleeding (paraplegia requiring laminectomy) has been estimated at 1: 1000000 [1] in patients without clinically apparent coagulation disorders. Only 61 cases of epidural haematoma associated with regional anaesthesia were reported in the world literature up to 1993, with 32 involving the use of an epidural catheter [2]. We report a further case and discuss the aetiological factors involved.

\section{Case history}

A 75-year-old, 78-kg male was transferred from a private hospital for further management of his ischaemic right leg. Three months previously he had surgery to repeat coronary artery bypass grafts following an episode of unstable angina and congestive cardiac failure. He had a markedly dilated left ventricle with an ejection fraction of $15 \%$ and had required an intra-aortic balloon pump to allow weaning from cardiopulmonary bypass. The balloon pump had been inserted into the right femoral artery and the right leg was noted to be cool and mottled in the recovery room. The balloon pump was removed and a femoral embolectomy performed with some improvement. This was followed 2 months later by a femoral-distal bypass procedure but this had to be revised due to thrombosis. A further thrombosis of the new superficial femoral artery graft resolved after treatment with urokinase and systemic heparinisation. However, the peroneal supply remained impaired and he developed ischaemic ulceration on his foot. The patient was transferred to our tertiary centre for evaluation and further management. His heparin therapy was continued to prevent further thrombosis. 
On examination in our hospital he was found to have clinical signs of congestive cardiac failure requiring additional treatment with diuretics. After additional vascular studies, the vascular surgeons elected to perform a right femoral-distal revascularisation procedure using cephalic vein.

Before surgery, his heparin infusion was discontinued for $7 \mathrm{~h}$ and coagulation studies (PT, APTT) were within normal limits, except for a lower than normal platelet count of $104 \times 10^{9} \cdot 1^{-1}$. After discussion with the patient and surgical team, it was agreed that epidural anaesthesia and analgesia would be a useful adjunct for surgery and general anaesthesia.

After attaching routine monitors (ECG, NIBP and pulse oximetry) a $14 \mathrm{G}$ cannula was inserted into a right arm vein. The patient received $5 \mathrm{mg}$ diazepam intravenously prior to the insertion of a $20 \mathrm{G}$ radial artery cannula. An epidural was then placed with the patient awake, in a sitting position, at the $\mathrm{L}_{2-3}$ level using a loss of resistance to saline technique and midline approach. Using an 18G Tuohy needle, the space was located at the first attempt and $4 \mathrm{~cm}$ of catheter inserted into the epidural space without any signs of vascular injury or paraesthesiae. After a negative aspiration test, a test dose of $4 \mathrm{ml} 1.5 \%$ lignocaine with 1:200000 adrenaline was given without any untoward effects. Epidural anaesthesia was established using $25 \mathrm{mg}$ bupivacaine to give a sensory level of $\mathrm{T}_{10}$. The patient was then taken to the operating theatre and positioned for surgery. After pre-oxygenation and intravenous fentanyl $3 \mu \mathrm{g} \cdot \mathrm{kg}^{-1}$, general anaesthesia was induced using etomidate $0.2 \mathrm{mg} . \mathrm{kg}^{-1}$ followed by pancuronium $0.1 \mathrm{mg} \cdot \mathrm{kg}^{-1}$. Following tracheal intubation, anaesthesia was maintained with isoflurane, oxygen and nitrous oxide. Ventilation was controlled mechanically to maintain normocapnia $(4.0-5.0 \mathrm{kPa})$. An epidural infusion of fentanyl $\left(2 \mu \mathrm{g} . \mathrm{ml}^{-1}\right)$ and bupivacaine $(0.125 \%)$ was used to maintain epidural anaesthesia and analgesia during surgery.

During the procedure the patient received a total of 20000 units of heparin in divided doses at the request of the surgeon. The first dose of 5000 units was given $2 \mathrm{~h}$ after the epidural insertion. Throughout the 8 -h procedure he remained haemodynamically stable and his trachea was extubated uneventfully in the operating room at the end of surgery. He was haemodynamically stable, pain free and moving all limbs. He was transferred to the surgical intensive care unit for observation and the acute pain service was notified to continue his epidural analgesia management.

In the unit, the surgeon requested a heparin infusion be started for thromboprophylaxis. Coagulation studies were performed twice daily to maintain a therapeutic level of heparin. The epidural infusion was changed to fentanyl
( $3 \mu \mathrm{g} \cdot \mathrm{ml}^{-1}$ ) and bupivacaine $0.0625 \%$ the following day in accordance with our usual practice. Neurological examination was carried out each morning for the first two postoperative days and was normal, and he continued to receive epidural analgesia and systemic heparin by infusion.

On the second postoperative day, it was decided to send the patient to the vascular laboratory for Doppler studies to document blood flow in the operated limb. This involved getting the patient out of bed and transferring him in a wheelchair to a department on another level of the hospital building. Upon his return to the ward he was examined by his attending surgeon who thought the motor power in his legs was reduced. He instructed his intern to ask for a review of his epidural analgesia. The intern duly requested help from the acute pain nurse who interpreted this request as an instruction to remove the epidural catheter. The epidural catheter was removed later that evening whilst the patient was fully anticoagulated with heparin.

The patient was not examined again until the next morning when he complained for the first time that he could not move his legs. On examination he was found to be paraplegic with a sensory level of $\mathrm{T}_{12}$ on the trunk. An urgent neurosurgical opinion was requested. A lumbar spine MRI scan was ordered but could not be performed due to the presence of pacing wires from his earlier cardiac surgery. CT scan findings were consistent with a possible epidural haematoma at the $\mathrm{L}_{1-2}$ level. A decompressive laminectomy was performed and an organised epidural clot with some fresh bleeding, extending posteriorly from $\mathrm{T}_{12}$ to $\mathrm{L}_{3}$, was removed. At the same operation, a femoral embolectomy was performed since the graft had thrombosed after the heparin infusion was discontinued. The patient recovered from his surgery and was discharged to a rehabilitation unit where minimal neurological recovery has occurred to date.

\section{Discussion}

We report this case to document a rare event and draw attention to the contentious issue of regional anaesthesia and anticoagulant therapy. Traditional textbook teaching is that the use of spinal or epidural anaesthesia is contraindicated in patients who are anticoagulated because of the rare possibility of producing a spinal haematoma.

Epidural haematomas can occur spontaneously and a review of such case reports over a 30-year period found 199 cases of which $20 \%$ were associated with anticoagulant therapy [3]. In comparison, a comprehensive Medline search of case reports of spinal haematomas associated with regional anaesthesia (from 1906 to 1994) identified a total of only 61 cases [2]. Of these 61 cases, Vandermuelen et al. note that $42(68 \%)$ were associated with impaired 
coagulation. In most instances $(n=30)$ some form of heparin therapy was in use. The remaining 12 patients had a variety of conditions including thrombocytopaenia (platelet count $<100 \times 10^{9} .1^{-1}$ ), chronic alcohol abuse, chronic renal failure, or were receiving aspirin or other antiplatelet medication at the time of bleeding. An epidural technique was used on 46 occasions, with an epidural catheter being placed in 32 cases. Overall, in 53/61 (87\%) cases, there were either puncture difficulties (multiple attempts/traumatic or bloody tap) or a coagulation disorder was present

In the context of anaesthesia for vascular surgery, patients are inevitably anticoagulated at some time in the peri-operative period and the risk of a spinal haematoma must be balanced against the benefits of epidural anaesthesia and analgesia for this patient population. Vascular surgical patients have been shown to be hypercoagulable compared with control patients prior to surgery. Postoperatively, this hypercoagulability has been shown to be attenuated by a general-epidural anaesthetic technique, resulting in a lower incidence of thrombotic events. The combination of general and epidural anaesthesia has also been shown to reduce cardiovascular, infectious and overall postoperative complications and intensive care stay [4].

Epidural anaesthesia is considered to be an important adjunct for revascularisation procedures of the lower extremities, since it has been shown to increase blood flow in the legs of patients with occlusive atherosclerotic disease [5] and reduce postoperative graft thrombosis [6].

The combination of a regional anaesthestic technique and anticoagulant therapy for peripheral vascular surgery has been reported by several investigators without incident [7, 8]. Rao and El-Etr [7] examined the incidence of neurological complications arising from anticoagulant therapy with heparin following epidural catheterisation in 3164 patients. Patients who had received pre-operative anticoagulation or who had blood dyscrasias or thrombocytopaenia were excluded. Intra-operatively, 50-60 min after placing the epidural, patients received heparin in carefully monitored incremental doses to maintain their activated clotting time at twice the baseline value. The heparin dose was repeated at 6-h intervals, following measurement of the activated clotting time, and the epidural catheters were removed $24 \mathrm{~h}$ after insertion $(1 \mathrm{~h}$ before the administration of the next heparin dose). Following surgery, no patient was reported to develop any symptoms or signs of epidural haematoma, although details of the postoperative epidural analgesia provided for these patients did not appear in their report.

Odoom and Sih [8] reported results from 1000 lumbar epidural blocks in patients having peripheral vascular surgery who were taking oral anticoagulant therapy.
They excluded patients who had blood dyscrasias, thrombocytopaenia or prior heparinisation. Patients received an intra-arterial heparin infusion for a short time $(<3 \mathrm{~h})$ and postoperatively the catheter was left in situ for $48 \mathrm{~h}$. None of the patients developed any neurological complications.

We considered epidural anaesthesia and analgesia to be important for this patient, especially in view of his repeated thrombotic episodes and cardiac status. We set out to perform his epidural as safely as possible in accordance with published guidelines $[8,13]$. His platelet count was lower than normal at $104 \times 10^{9} \cdot 1^{-1}$ but we did not consider that this would significantly affect his coagulation status. His other clotting tests (PT, APTT) were in the normal range and his heparin had been stopped for $7 \mathrm{~h}$ prior to epidural insertion.

Postoperatively, his heparin therapy was monitored to maintain his APTT twice the normal value. The epidural infusion provided good analgesia, without any sign of complication, until the second postoperative day. On this day, after his return to the ward following a transfer, he was examined by his surgeon who thought his legs were weak and attributed this to the epidural analgesia. These findings contrasted with the normal power in the legs documented prior to leaving the ward. The surgeon gave verbal instructions to ask for his epidural to be reviewed, but the verbal request received subsequently by the acute pain nurse was that the epidural should be removed.

As a result, the epidural catheter was removed that evening whilst the heparin infusion was still in progress and his APTT was twice normal. His neurological examination prior to removal of the epidural was not documented. The next morning, he complained that he could not move his legs and was paraplegic on examination.

It would seem likely that the vessel damage leading to the epidural haematoma occurred on the second postoperative day, the cause being either a spontaneous event, a result of catheter migration or movement at the time of his transfer, or following the removal of his catheter whilst anticoagulated with heparin. Catheter migration has been documented in association with active movement [9] and the literature includes a single report where manipulation of an epidural catheter in a patient on heparin led to the development of an epidural haematoma with cord compression [10]. Other case reports identify the removal of an epidural catheter as the initiating factor in epidural haematoma formation $[11,12]$. Vandermuelen found that spinal bleeding occurred immediately after removal of the epidural catheter in 15 of the 32 cases that he reviewed [2]. Nine of these catheters were removed at a time when patients had therapeutic plasma levels of heparin and a further three catheters were removed within $2 \mathrm{~h}$ of stopping heparinisation. We can only speculate that the removal of the catheter resulted in the haematoma in 
our case, since the patient did not complain of leg weakness until the morning after this occurred. Guidelines for the safe removal of epidural catheters state that heparin should be stopped 1-2 h prior to removal [13].

The limited data available would seem to suggest that with normal coagulation and an atraumatic epidural catheter placement, the use of pre-operative and intraoperative anticoagulation is safe. Postoperatively, concurrent use of anticoagulation in the presence of an epidural catheter has a greater risk of producing an epidural haematoma. These cases require regular neurological assessment to detect signs of a developing haematoma.

Vandermuelen notes that the first complaint of $46 \%$ of patients with a spinal haematoma was muscle weakness, followed by back pain (38\%) and a sensory deficit (14\%) [2]. He advocates allowing any epidural blockade to wear off at intervals to avoid masking symptoms. Delayed identification and treatment of haematoma was associated with a poor neurological outcome. Complete recovery of neurological function is possible if surgery is performed within $8 \mathrm{~h}$ of the onset of paraplegia. Neurological outcome is also influenced by the localisation of the haematoma; due to the poor vascular supply of the dorsal part of the cord, haematomas in this area are associated with poor neurological recovery [2].

Epidural catheter insertion and removal should be timed to be performed when coagulation is normal. We suggest that, if anticoagulant therapy is given following placement of an epidural catheter, active movement of such patients should be minimised to prevent migration of the epidural catheter causing vessel damage. The communication failure that led to the inadvertent removal of the epidural catheter in our case has prompted a change in protocol to prevent a similar event occurring in the future.

On a wider scale, epidural catheters are also commonly used to provide postoperative analgesia following general and orthopaedic surgery. These patients are often given thromboprophylaxis for their surgery in the form of a lowmolecular-weight heparin (LMWH). The pharmacodynamics of these drugs differ to those of heparin and include an onset of $90 \mathrm{~min}$, half-lives of more than $4 \mathrm{~h}$ and antithrombotic effects that last up to $12 \mathrm{~h}$ [15]. Peak plasma levels of heparin sodium given subcutaneously are achieved in $2-4 \mathrm{~h}$, although there are considerable individual variations. An intravenous bolus results in immediate anticoagulant effects. Heparin is rapidly cleared from plasma with an average half-life of $1-2 \mathrm{~h}$. Half-life is dose dependent and may be significantly prolonged at higher doses (56 min at 100 unit. $\mathrm{kg}^{-1}$ cf. $152 \mathrm{~min}$ at 400 unit. $\mathrm{kg}^{-1}$ ) [16].

The U.S. Food and Drug Administration (FDA) has recently issued an advisory notice to health care professionals regarding the concurrent use of LMWH and spinal/epidural anaesthesia [14]. The FDA action is a response to more than 30 reports (since 1993) of patients who developed spinal/epidural haematomas following concurrent use of enoxaparin, a low-molecular-weight heparin, and neuraxial anaesthesia. The majority involved dosing the anticoagulant either pre-operatively or immediately postoperatively. Only two cases have been reported in Europe where the recommended dosage regimen is lower (20 or $40 \mathrm{mg}$ in Europe vs. $60 \mathrm{mg}$ daily in the USA) [1]. Published guidelines suggest allowing a time interval of at least $8 \mathrm{~h}$ before/after a dose of LMWH prior to any spinal/epidural procedure [1]. This represents two halflives and the equivalent for standard heparin would therefore be a time interval of $2-4 \mathrm{~h}$. Wildsmith and McClure [13] have suggested that $4-6 \mathrm{~h}$ is a safe interval following administration of subcutaneous heparin before instituting a block. It appears logical to suggest that removal of a catheter should follow the same conditions as catheter insertion, i.e. allow $4-6 \mathrm{~h}$ after a dose of subcutaneous heparin. For safe catheter removal, the same authors suggest that intravenous heparin should be stopped for $1-2 \mathrm{~h}$ only. If we accept that the same conditions should apply for catheter insertion, is a $1-2 \mathrm{~h}$ interval between stopping a heparin infusion and instituting a block adequate? This latter time interval represents one half-life and we suggest it is too short. A minimum time interval of two half-lives, or $4 \mathrm{~h}$, may be more appropriate.

\section{References}

1 Tryba M, Wedel DJ. Central neuroaxial block and low molecular weight heparin: Lessons learned from different dosage regimes in two continents. Acta Anaesthesiologica Scandinavia 1997; 41 (Suppl. 111): 100-3.

2 Vandermuelen EP, Van Asken H, Vermylen J. Anticoagulants and Spinal-Epidural anaesthesia. Anesthesia and Analgesia 1994; 79: 1165-77.

3 Groen RJM, Ponssen H. The spontaneous spinal epidural haematoma: a study of the etiology. Journal of the Neurological Sciences 1990; 98: 121-38.

4 Tuman KJ, et al. Effects of Epidural anesthesia and analgesia on coagulation and outcome after major vascular surgery. Anesthesia and Analgesia 1991; 73: 696-704.

5 Hljamae H, Frid I, Holm J, Akerstrom G. Epidural anaesthesia versus general anaesthesia and leg blood flow in patients with occlusive atherosclerotic disease. European Journal of Vascular Surgery 1988; 2: 395-400.

6 Christopherson R, et al. Perioperative morbidity in patients randomised to epidural or general anesthesia for lower extremity vascular surgery. Anesthesiology 1993; 79: 422-34.

7 Rao TLK, El-Etr AA. Anticoagulation following placement of epidural and subarachnoid catheters. Anesthesiology 1981; 55: 618-20.

8 Odoom JA, Sih IL. Epidural analgesia and anticoagulant therapy: Experience with one thousand cases of continuous epidurals. Anaesthesia 1983; 38: 254-9. 
9 Phillips DC, MacDonald R. Epidural catheter migration in labour. Anaesthesia 1987; 42: 661-3.

10 Usubiaga JE. Neurological complications following epidural anesthesia. International Anesthesiology Clinics 1975; 13: 43.

11 Tekkok IH, Catalepe O, Tahta K, Bertran V. Extradural haematoma after continuous extradural anaesthesia. British Journal of Anaesthesia 1991; 67: 112-5.

12 Onishchuk JL, Carlsson C. Epidural haematoma associated with epidural anaesthesia: complications of anticoagulant therapy. Anesthesiology 1992; 77: 1221-3.
13 Wildsmith JAW, McClure JH. Anticoagulant drugs and central nerve blockade. Anaesthesia 1991; 46: 612-3.

14 Food and Drug Administration. Health Advisory for Certain Anticoagulant Drugs (Low Molecular Weight Heparins and Heparinoids) Talk Paper.T97-63. 15 December, 1997. Http://www.fda.gov/bbs/topics/ANSWERS/ ANS00839.html

15 Vandepol C. Enoxaparin and epidural anesthesia. Anesthesiology 1996; 85: 433-4.

16 McEvoy GK. American Hospital Formulary Service. Drug information 1997, 1086.

\title{
CASE REPORT \\ The use of remifentanil in general anaesthesia for Caesarean section in a patient with mitral valve disease
}

\author{
H. Scott, ${ }^{1}$ C. Bateman ${ }^{2}$ and M. Price ${ }^{3}$ \\ 1 Senior Registrar Specialist, 2 Registrar and 3 Consultant, Department of Anaesthesia, St Mary's Hospital, Praed Street, \\ London W2 1NY, UK
}

\begin{abstract}
Summary
We report the use of remifentanil as part of a general anaesthetic technique for a patient with mixed mitral valve disease, asthma and pre-eclampsia presenting for an emergency Caesarean section. The use of remifentanil was associated with stable haemodynamic variables during general anaesthesia. No clinically significant respiratory depression was noted in the neonate.
\end{abstract}

Keywords Complications; mitral valve disease. Surgery; Caesarean section. Analgesics; remifentanil.

Correspondence to: Dr H. Scott

Accepted: 5 February 1998

Remifentanil is a newly introduced synthetic opioid. It has an extremely short duration of action, being metabolised by nonspecific plasma esterases. It is a potent opioid agonist and produces intense analgesia and sedation. A major benefit of remifentanil is its context sensitive half-life of $3 \mathrm{~min}$, which is consistent regardless of the duration of the infusion [1]. We report the use of remifentanil as part of a general anaesthetic technique for an emergency Caesarean section in a patient with asthma, mixed mitral valve disease and pre-eclampsia.

\section{Case history}

The patient was a 38-year-old woman with mixed mitral valve disease secondary to rheumatic fever in childhood.
She had a long history of asthma and was markedly obese, with a body mass index of 36.5 (weight: $90 \mathrm{~kg}$, height: $157 \mathrm{~cm}$ ). On pre-operative examination, she was found to have a short neck and airway assessment was scored as a Mallampati grade 2. Her four previous pregnancies had been complicated by pregnancy-induced hypertension. All resulted in assisted vaginal deliveries after induction of labour.

She was admitted to hospital at 28 weeks' gestation with shortness of breath. This was diagnosed as an infective exacerbation of her asthma complicated by pulmonary oedema. She was treated with bronchodilator inhalers, antibiotics and steroids. Echocardiography showed moderate to severe mitral regurgitation with mild mitral stenosis. Of particular concern was the hypertrophy of 
the left atrium and ventricle, the atrium increasing in diameter from $4.7 \mathrm{~cm}$ to over $7.0 \mathrm{~cm}$ in the second and third trimesters. At 36 weeks' gestation she developed another chest infection. At this point digoxin was started as prophylaxis against the development of atrial fibrillation. Her heart remained in sinus rhythm until the day of delivery. As in her previous pregnancies, her blood pressure increased by 35 weeks' gestation, from $130 / 90 \mathrm{mmHg}$ at booking to $150 / 100 \mathrm{mmHg}$. She developed proteinuria at 38 weeks' gestation. Before delivery, her regular medication comprised amlodipine, frusemide, digoxin, terbutaline, budesonide and salbutamol inhalers.

It was decided to induce labour at 38 weeks because of increasing breathlessness, frequent atrial ectopic beats, increasing blood pressure and proteinuria, and this was achieved with a dinoprostone pessary. Elective central venous pressure monitoring was instituted with a right internal jugular venous line after exclusion of thrombocytopaenia and coagulopathy. She was unable to lie flat during central venous line insertion because of breathlessness. An epidural was inserted with the patient in the sitting position. A mixture of bupivacaine $0.1 \%$ and fentanyl $2 \mu \mathrm{g} \cdot \mathrm{ml}^{-1}$ was injected down the epidural catheter in small incremental doses to provide analgesia.

The combination of slow progress in labour, a short episode of atrial fibrillation, oliguria and a cardiotocograph trace suggestive of fetal distress led to the decision to proceed urgently to Caesarean section. The patient was transferred to an operating theatre with immediate access to cardiothoracic surgeons and intensive care facilities. She had received antacid prophylaxis in the form of ranitidine $150 \mathrm{mg}$ and metoclopramide $10 \mathrm{mg}$ orally $2 \mathrm{~h}$ previously.

In view of her cardiovascular condition, her inability to lie flat and the need for urgent delivery, a general anaesthetic technique was preferred to a rapid extension of her epidural block. A radial arterial line was inserted before induction of anaesthesia. Following pre-oxygenation, a modified rapid sequence induction was performed using remifentanil $2 \mu \mathrm{g} \cdot \mathrm{kg}^{-1}$, etomidate $20 \mathrm{mg}$ and suxamethonium $100 \mathrm{mg}$. The patient's trachea was intubated with an 8.0-mm internal diameter cuffed tracheal tube using a gum elastic bougie. Anaesthesia was maintained with intermittent positive pressure ventilation using nitrous oxide, oxygen and isoflurane. Vecuronium $6 \mathrm{mg}$ was given when the effect of the suxamethonium had worn off. Analgesia was provided by a remifentanil infusion running initially at $800 \mu \mathrm{g} \cdot \mathrm{h}^{-1}\left(0.15 \mu \mathrm{g} \cdot \mathrm{kg}^{-1} \cdot \mathrm{min}^{-1}\right)$ and then reduced to $400 \mu \mathrm{g} \cdot \mathrm{h}^{-1}\left(0.075 \mu \mathrm{g} \cdot \mathrm{kg}^{-1} \cdot \mathrm{min}^{-1}\right)$ after tracheal intubation and surgical incision.

Anaesthesia and surgery proceeded uneventfully and lasted $45 \mathrm{~min}$. On arrival in the operating theatre, the patient's blood pressure was $177 / 99 \mathrm{mmHg}$, with a heart rate of 131 beat. $\mathrm{min}^{-1}$. Laryngoscopy and intubation were performed without any increase in blood pressure and her heart remained in sinus rhythm throughout. At the time of delivery, her blood pressure was $125 / 82 \mathrm{mmHg}$, with a heart rate of 112 beat. $\mathrm{min}^{-1}$. For the rest of the operation, her blood pressure remained between 113 and $134 \mathrm{mmHg}$ systolic, between 72 and $89 \mathrm{mmHg}$ diastolic and her heart rate was between 105 and 113 beat.min ${ }^{-1}$. The total dose of remifentanil given intra-operatively was $480 \mu \mathrm{g}$.

A live male infant was delivered $3 \mathrm{~min}$ after induction of anaesthesia. The baby made spontaneous respiratory efforts within $30 \mathrm{~s}$. Apgar scores were 6 at $1 \mathrm{~min}$ and 8 at 5 and $10 \mathrm{~min}$. The paediatricians commented on the lack of respiratory depression in view of the opioid given to the mother.

The patient was transferred immediately to the intensive care unit for postoperative monitoring. The remifentanil infusion was increased to $0.15 \mu \mathrm{g} \cdot \mathrm{kg}^{-1} \cdot \mathrm{min}^{-1}$ after discontinuation of nitrous oxide and isoflurane. Blood pressure and heart rate remained stable during the immediate postoperative period. Bupivacaine 0.1\% was administered slowly via the epidural to establish a sensory block prior to weaning the remifentanil infusion. Ten minutes after stopping the infusion and $90 \mathrm{~min}$ after the end of the operation, her trachea was extubated. Bronchospasm did not occur during anaesthesia or on emergence or extubation of the trachea.

The patient was monitored on the intensive care unit for $24 \mathrm{~h}$. She remained cardiovascularly stable, had no respiratory problems and was able to be discharged to the post natal ward. The epidural catheter was then removed and subsequent analgesia provided using paracetamol and codeine phosphate given orally.

\section{Discussion}

This patient presented the anaesthetists with several problems; her compromised cardiovascular function, her chest infection and asthma, her pre-eclamptic signs and evidence of fetal distress. The choice of anaesthetic was between a regional technique, using her existing epidural, and general anaesthesia. Although she had been comfortable in labour, when the decision to perform the Caesarean section was made the sensory block provided by the epidural was only at $\mathrm{T}_{10}$ when tested with ethyl chloride spray. We rejected the epidural option because rapid extension of the block could have caused sympathetic blockade and a sudden decrease in systemic vascular resistance, which may have affected her cardiovascular function. In view of the urgency of the situation a gradual extension of the block was contraindicated. In addition, she was unable to lie flat (despite lateral tilt) due to breathlessness, and would have been very uncomfortable during the operation. 
General anaesthesia was therefore preferred. We were concerned that a technique such as the standard rapid sequence induction of anaesthesia followed by maintenance using nitrous oxide and a volatile agent would result in a significant response to tracheal intubation and compromise control over cardiovascular parameters. Opioidbased techniques are recommended for anaesthesia in patients with valvular disease as they have a minimally depressive action on the cardiovascular system and provide excellent analgesia [2,3]. Remifentanil has been used for cardiac surgery $[4,5]$, where it combines the requirement for intra-operative control of stress responses and rapid recovery. In major abdominal surgery [6] it has been shown to be associated with significantly less response to tracheal intubation, skin incision and surgery than alfentanil. Remifentanil does not have a product licence for use in obstetrics, but informed verbal consent was obtained from the patient for its use.

High doses of commonly used opioids cause significant respiratory depression. As this patient was asthmatic and prone to chest infections, early extubation of her trachea was desirable. Postoperatively the remifentanil infusion rate was $0.15 \mu \mathrm{g} \cdot \mathrm{kg}^{-1} \cdot \mathrm{min}^{-1}$, and she was indeed apnoeic (although awake enough to respond to commands and questions about her pain). With rapid metabolism and clearance of remifentanil from the circulation, spontaneous respiration returned $4 \mathrm{~min}$ after stopping the infusion and her trachea was extubated uneventfully 6 min later.

Postoperative analgesia was achieved initially with a remifentanil infusion until re-establishment of epidural blockade. In a comparison of remifentanil and alfentanil during and after major abdominal surgery [6] there was a significant incidence of apnoea and muscle rigidity, mainly due to rapid bolus doses or a large increase in infusion rate given to control pain, which was experienced frequently on cessation of the infusion. Whilst the patient was still being invasively monitored and her lungs were being ventilated, this did not present a problem. In order to achieve spontaneous respiration as well as analgesia, we gave plain bupivacaine $0.1 \%$ until she was able to indicate a sensory level at $\mathrm{T}_{6}$. At this point the remifentanil infusion was stopped.

A major concern in the use of opioids in this setting is placental transfer to the neonate causing respiratory depression [7]. Significant respiratory depression in the neonate did not occur in this case. In similar situations [8, 9], alfentanil was used with a successful maternal outcome, but the neonate required naloxone to reverse the associated respiratory depression. Two studies have shown that remifentanil used during Caesarean section [10] and for postoperative analgesia in neonates [11] has similar pharmacokinetics in neonates as in older children and adults. Thus respiratory depression in the neonate is transitory as the remifentanil is rapidly metabolised.

In conclusion, we have reported a case where remifentanil was used as part of a general anaesthetic technique for an emergency Caesarean section and provided stable cardiovascular parameters whilst not compromising respiratory function in either mother or baby. Remifentanil, with its context sensitive half-life of $3 \mathrm{~min}$ and documented cardiovascular stability in cardiac and major abdominal surgery, appears to have an ideal profile for use in this situation.

\section{References}

1 Michelson LG, Hug CC. The pharmacokinetics of remifentanil. Journal of Clinical Anaesthesia 1996; 8: 679-82.

2 Hemmings HC, Thomas SJ. Management of patients with valvular heart disease. In: Prys-Roberts C, Brown BR. International Practice of Anaesthesia. Oxford: Butterworth Heinemann, 1996; Chapter 39, 11-13.

3 Bovill JG, Warren PJ, Schuller JL, van Wezel HB, Hoeneveld $\mathrm{MH}$. Comparison of fentanyl, sufentanil and alfentanil anaesthesia in patients undergoing valvular heart surgery. Anesthesia and Analgesia 1994; 63: 1081-6.

4 Royston D. Remifentanil in cardiac surgery. European Journal of Anaesthesiology 1995; 10 (Suppl.): 77-9.

5 Servin F. Remifentanil: when and how to use it. European Journal of Anaesthesiology 1997; 15 (Suppl.): 41-4.

6 Schuttler J, Albrecht S, Breivik H, et al. A comparison of remifentanil and alfentanil in patients undergoing major abdominal surgery. Anaesthesia 1997; 52: 307-17.

7 Thorburn J, Reid J. Physiology of pregnancy and the placenta. In: Prys-Roberts C, Brown BR. International Practice of Anaesthesia. Oxford: Butterworth Heinemann, 1996; Chapter 94, 8-9.

8 Batson MA, Longmire S, Csontos E. Alfentanil for urgent Caesarean section in a patient with severe mitral stenosis and pulmonary hypertension. Canadian Journal of Anaesthesia 1990; 37: 685-8.

9 Redfern N, Bower S, Bullock RE, Hull CJ. Alfentanil for Caesarean section complicated by severe aortic stenosis. A case report. British Journal of Anaesthesia 1987; 59: 1309-12.

10 Hughes SC, Kan RE, Rosen MA, et al. Remifentanil: ultra-short acting opioid for obstetric anaesthesia. Anesthesiology 1996; 85: A894.

11 Davis PJ, Ross AK, Henson LG, Muir KT. Remifentanil pharmacokinetics in neonates. Anesthesiology 1997; 87: A1054. 


\title{
CASE REPORT \\ The management of metformin overdose
}

\author{
K. F. H. Teale, ${ }^{1}$ A. Devine, ${ }^{2}$ H. Stewart ${ }^{1}$ and N. J. H. Harper ${ }^{1}$ \\ 1 Department of Anaesthesia, Manchester Royal Infirmary, Oxford Road, Manchester M13 9WL, UK \\ 2 Department of Anaesthesia, Royal Liverpool Hospital, Prescot Street, Liverpool L7 8XP, UK
}

\begin{abstract}
Summary
Only two cases of deliberate self-poisoning with metformin have been described in the literature. We report the management of three cases, all of which presented with severe lactic acidosis. Two cases had a fatal outcome. The options for treatment and previous cases reported in the literature are reviewed. Recommendations for the management of metformin overdose include early recognition, intensive support of the cardiovascular system, the correction of metabolic acidosis and the maintenance of body temperature. The use of venovenous haemofiltration against a nonlactate containing fluid may improve outcome when sodium bicarbonate alone fails to reverse severe systemic acidosis.
\end{abstract}

Keywords Metabolism; lactic acidosis, diabetes mellitus. Pharmacology; metformin.

Correspondence to: Dr H. Stewart

Accepted: 18 July 1997

There are few descriptions of metformin overdose in the literature [1, 2], although lactic acidosis is a well-recognised side-effect of metformin administration in noninsulin dependent diabetics [3-5]. The three cases described here occurred within 18 months. Two cases had a fatal outcome. Current recommendations for the management of metformin overdose include treatment of the acidosis with sodium bicarbonate and prevention of further drug absorption by charcoal gastric lavage. However, there is little emphasis on supporting the cardiovascular system. We believe that current recommendations for treatment should be revised.

\section{Case histories}

Case 1

A 25-year-old, previously fit, non-insulin dependent diabetic male with sickle-cell trait was brought to the Accident and Emergency Department after having taken an unknown number of metformin tablets. He had been lying semiconscious at home for at least $8 \mathrm{~h}$. He was confused, his blood pressure was $70 / 50 \mathrm{mmHg}$, his heart rate was 100 beats. min $^{-1}$ and his peripheral oxygen saturation was $95 \%$ on $60 \%$ oxygen by mask. He was hyperventilating and had a metabolic acidosis. Arterial blood gases were: $\mathrm{pH} 7.1, \mathrm{PaCO}_{2} 4.7 \mathrm{kPa}$, plasma bicarbonate $10 \mathrm{mmol} . \mathrm{l}^{-1}$. Plasma lactate was $10.8 \mathrm{mmol} . \mathrm{l}^{-1}$ and blood glucose was $0.3 \mathrm{mmol}^{-1}$. Sodium bicarbonate $8.4 \%$ $100 \mathrm{ml}$ and glucose $50 \% 50 \mathrm{ml}$ were given intravenously. Gastric lavage was attempted but was abandoned because of the patient's agitation. Plasma paracetamol and salicylate assays were negative. The patient was hypotensive, agitated and not responding to command. His trachea was intubated and charcoal gastric lavage was performed. A urinary catheter and pulmonary artery catheter were inserted. His core temperature at this time was $31^{\circ} \mathrm{C}$ and arterial blood gas results were: $\mathrm{pH} 6.79$, base deficit 33 and plasma bicarbonate $2.1 \mathrm{mmol}^{-1}$.

The first haemodynamic readings in the intensive care unit (ICU) showed a systemic vascular resistance (SVR) of 219 dyne.s. $\mathrm{cm}^{-5}$ and a cardiac index of $3.31 . \mathrm{min}^{-1} \cdot \mathrm{m}^{-2}$. Despite starting infusions of noradrenaline (initially at $10 \mu \mathrm{g} \cdot \mathrm{min}^{-1}$ and increased to $40 \mu \mathrm{g} \cdot \mathrm{min}^{-1}$ ) and adrenaline (at $5 \mu \mathrm{g} \cdot \mathrm{kg}^{-1} \cdot \mathrm{min}^{-1}$ ), a significant increase in SVR could not be produced. Owing to the increasing acidosis, it was decided to use venovenous haemodiafiltration to speed correction of the acidosis (he was considered too haemodynamically unstable to tolerate haemodialysis). Venovenous diafiltration was commenced via a double-lumen femoral dialysis line. The dialysate fluid was normal saline 
and replacement fluid was initially plasma then $4 \%$ dextrose $/ 0.45 \%$ saline.

Infusion of sodium bicarbonate $8.4 \%$ was continued at $100 \mathrm{ml} . \mathrm{h}^{-1}$. After $2 \mathrm{~h}$ of filtration, the systemic $\mathrm{pH}$ had increased to 6.91 with a plasma bicarbonate of $5.2 \mathrm{mmol} . \mathrm{l}^{-1}$. However, blood lactate had risen dramatically to $25 \mathrm{mmol} \cdot \mathrm{l}^{-1}$. The patient required large doses of noradrenaline to maintain a systolic blood pressure of $90 \mathrm{mmHg}$ and the SVR could not be increased to above 250 dyne.s. $\mathrm{cm}^{-5}$. It was not possible to increase the patient's core temperature. An additional problem was a rapid fall in haemoglobin concentration to 5 g.dl ${ }^{-1}$, requiring a transfusion of 8 units of blood.

The patient's condition gradually deteriorated. An arterial blood $\mathrm{pH}$ of greater than 6.9 could not be obtained, the plasma lactate level remaining at $24 \mathrm{mmol}^{-1}$. Plasma sodium increased to $163 \mathrm{mmol} \cdot \mathrm{l}^{-1}$. His heart became asystolic after a further $12 \mathrm{~h}$. The stated cause of death at post-mortem was multi-organ failure.

\section{Case 2}

A 60-year-old non-insulin dependent diabetic was admitted to the Accident and Emergency Department $12 \mathrm{~h}$ after taking 20 ibuprofen $400 \mathrm{mg}$ tablets, 100 metformin $500 \mathrm{mg}$ tablets and 20 glibenclamide $5 \mathrm{mg}$ tablets. He had vomited repeatedly before admission and was complaining of severe central abdominal pain radiating to his back. He was tachypnoeic, agitated and drowsy. Blood pressure was $140 / 70 \mathrm{mmHg}$, heart rate 104 beats. $\mathrm{min}^{-1}$ and blood sugar $7 \mathrm{mmol}^{-1}$. Arterial blood gases at this time showed a severe metabolic acidosis with a $\mathrm{pH}$ of 6.9 and a base deficit of $28.4 \mathrm{mmol}^{-1}$, $\mathrm{PaCO}_{2} 2.6 \mathrm{kPa}$, plasma bicarbonate $4.0 \mathrm{mmol} . \mathrm{l}^{-1}$ and plasma lactate $29 \mathrm{mmol}^{-1} \mathrm{l}^{-1}$. An infusion of sodium bicarbonate $8.4 \%$ was started.

Just before transfer to the intensive care unit (ICU), the patient became apnoeic and his heart went into ventricular fibrillation. Sinus rhythm was restored following a $200 \mathrm{~J}$ DC shock and adrenaline $2 \mathrm{mg}$ but no respiratory effort was observed. The patient was taken to the ICU for his lungs to be mechanically ventilated. A pulmonary artery catheter was inserted. The core temperature was $31^{\circ} \mathrm{C}$. Mean arterial pressure was $48 \mathrm{mmHg}$, cardiac index 5.91. $\mathrm{min}^{-1} . \mathrm{m}^{-2}$ and SVR 209 dyne.s. $\mathrm{cm}^{-5}$. The patient became anuric.

An infusion of noradrenaline was started at $90 \mu \mathrm{g} \cdot \mathrm{min}^{-1}$, which increased the SVR to 600 dyne.s. $\mathrm{cm}^{-5}$. Intravenous sodium bicarbonate $8.4 \%$ was started at $250 \mathrm{mmol} . \mathrm{h}^{-1}$ for $3 \mathrm{~h}$. The $\mathrm{pH}$ increased to 7.2, with a base deficit of 14 and bicarbonate of $11 \mathrm{mmol} . \mathrm{l}^{-1}$ but the lactate increased to $32 \mathrm{mmol} .1^{-1}$ and plasma sodium to $162 \mathrm{mmol} . \mathrm{l}^{-1}$. Thirty hours after the poisoning, venovenous haemodiafiltration was started via a double lumen subclavian dialysis line. Anticoagulation was instituted with heparin $2500 \mathrm{IU} . \mathrm{h}^{-1}$ and epoprostenol $5 \mu \mathrm{g} \cdot \mathrm{kg}^{-1} \cdot \mathrm{min}^{-1}$. The haemofiltration pump speed was $120 \mathrm{ml} \cdot \mathrm{min}^{-1}$ and the hourly filtrate output was $800 \mathrm{ml} \cdot \mathrm{h}^{-1}$. Both the dialysate and replacement fluid were Ringer's sodium solution for the first $5 \mathrm{~h}$, after which the dialysate was changed to Dianeal with glucose $1.36 \%$.

After $10 \mathrm{~h}$ of diafiltration, plasma lactate had decreased to $18 \mathrm{mmol}^{-1}$ and plasma sodium to $148 \mathrm{mmol} \cdot \mathrm{l}^{-1}$. The arterial blood $\mathrm{pH}$ steadily increased. The patient continued to be dialysed for $72 \mathrm{~h}$, at which time he became polyuric. During the first 6 days, the patient was unstable with a very low SVR poorly responsive to noradrenaline but with a cardiac index more than $4.51 \cdot \mathrm{min}^{-1} \cdot \mathrm{m}^{-2}$. Plasma urea and creatinine peaked on the seventh day at $19 \mathrm{mmol} . \mathrm{l}^{-1}$ and $526 \mu \mathrm{mol} . \mathrm{l}^{-1}$, respectively. These values then decreased with no further diafiltration and returned to normal levels by the thirteenth day. The patient subsequently made a good recovery and was discharged from ICU after 13 days.

\section{Case 3}

A 33-year-old non-insulin dependent diabetic was admitted to the Accident and Emergency Department having taken 70 metformin $500 \mathrm{mg}$ tablets $4 \mathrm{~h}$ previously. She was vomiting, complaining of severe back pain and having episodes of diarrhoea. She was conscious and alert, with a respiratory rate of 40 breaths. $\mathrm{min}^{-1}$, heart rate 100 beats.min ${ }^{-1}$ and blood pressure $100 / 70 \mathrm{mmHg}$. Arterial blood gases showed a severe metabolic acidosis (pH 6.9, plasma bicarbonate $5.1 \mathrm{mmol}^{-1}$, base deficit 25, $\mathrm{PaCO}_{2} 2.9 \mathrm{kPa}$ ). After discussion with the Leeds Poison Centre, she was given oral activated charcoal and intravenous sodium bicarbonate $1.4 \%$ at $200 \mathrm{ml} . \mathrm{h}^{-1}$. She was transferred to a medical ward.

Seven hours later, she became agitated and complained of tingling in her hands and feet and visual disturbance. The blood glucose was $2 \mathrm{mmol}^{-1}$ and dextrose $50 \%$ $50 \mathrm{ml}$ was given intravenously. Arterial blood gases at this time showed an increasing metabolic acidosis (pH 6.8, base deficit 25). She was transferred to the ICU.

In the ICU her trachea was intubated and her lungs were mechanically ventilated in view of an increasing respiratory rate and increasing acidosis ( $\mathrm{pH}$ of 6.7). Mean arterial pressure fell to $60 \mathrm{mmHg}$ and a pulmonary artery catheter was inserted, which provided the following data: $\mathrm{SVR}=500$ dyne.s. $\mathrm{cm}^{-5}$, cardiac index $=3.91$. $\min ^{-1} \cdot \mathrm{m}^{-2}$ and pulmonary artery occlusion pressure $=9 \mathrm{mmHg}$. The core temperature was $32.1^{\circ} \mathrm{C}$. An infusion of noradrenaline was started. Sodium bicarbonate $8.4 \%$ was infused at $200 \mathrm{ml} . \mathrm{h}^{-1}$ but was stopped after $11 \mathrm{~h}$ when the plasma sodium rose to $162 \mathrm{mmol} . \mathrm{l}^{-1}$. The acidosis improved briefly to a maximum $\mathrm{pH}$ of 7.07 but 
$\mathrm{pH}$ decreased again when the bicarbonate infusion was stopped.

Ten hours after admission to ICU, the patient became anuric and, as facilities for haemofiltration were not available, she was accepted for haemofiltration at another hospital. Despite further increases in noradrenaline infusion rate to $2.2 \mu \mathrm{g} \cdot \mathrm{kg}^{-1} \cdot \mathrm{min}^{-1}$, SVR and arterial blood pressure remained low (SVR $=295$ dyne.s. $\mathrm{cm}^{-5}$, mean arterial blood pressure $=50 \mathrm{mmHg}$ ) and she was judged too unstable to transfer. An adrenaline infusion was started and the rate was increased gradually to $4.6 \mu \mathrm{g} \cdot \mathrm{kg}^{-1} \cdot \mathrm{min}^{-1}$. Phenylephrine at $1.6 \mu \mathrm{g} \cdot \mathrm{kg}^{-1} \cdot \mathrm{min}^{-1}$ was started with no improvement in haemodynamic indices. Thirty-six hours after admission, mean arterial pressure was $25 \mathrm{mmHg}$ and cardiac output was not measurable. The decision to withdraw inotropic treatment was made and she died $2 \mathrm{~h}$ later.

\section{Discussion}

Metformin is the only biguanide available in the UK (phenformin was withdrawn in 1982 because of its tendency to cause spontaneous lactic acidosis). Biguanides lower blood glucose levels, reducing the intestinal absorption of glucose, decreasing gluconeogenesis and increasing the peripheral utilization of glucose. This group of drugs can cause type B lactic acidosis by increasing lactic acid production peripherally whilst impairing its removal by the liver and kidneys [6]. A literature search revealed only two case reports of deliberate biguanide overdose [1, 2]. Both cases presented with vomiting, epigastric pain and normal plasma biochemistry but went on to develop severe metabolic acidosis after 4-9h (arterial blood $\mathrm{pH}$ of 6.88 and 6.95). Neither patient developed cardiovascular collapse. Both were treated with infusions of sodium bicarbonate $8.4 \%(650 \mathrm{mmol}$ over $10 \mathrm{~h}$ in one case and $850 \mathrm{mmol}$ over $11 \mathrm{~h}$ in the other). Arterial blood $\mathrm{pH}$ returned to normal and both patients recovered. Management also included intravenous fluids and frusemide to produce a diuresis, as metformin is excreted unchanged in the urine. Our patients differed from these reports in that although two presented initially with normal cardiovascular parameters, all three developed severe cardiovascular collapse, leading to type A lactic acidosis in addition to the metformin-induced acidosis.

Correction of metabolic acidaemia is central to treatment. Sodium bicarbonate is the most commonly used agent but there are well-known problems associated with its use. Even large doses of sodium bicarbonate alone failed to produce a sustained increase in blood $\mathrm{pH}$ in our patients owing to the extremely rapid tissue production of lactate in conditions of circulatory insufficiency and tissue ischaemia. Sodium bicarbonate administration is invariably associated with a large sodium load. In addition, it can lead to a paradoxical worsening of intracellular acidosis [7]. Other methods of treating metabolic acidosis include dichloroacetate, which acts by activating pyruvate dehydrogenase, enhancing the rate-limiting step in the oxidative metabolism of lactate. Dichloroacetate has been shown to prevent or reverse hyperlactataemia induced in animals by phenformin administration. However, work carried out in man suggests that although it may transiently improve acidaemia, the mortality rate is not affected [8].

Another alkalinising agent used in the UK is THAM (tri-hydroxymethyl aminomethane). This is an organic amine proton acceptor. It is mainly used during cardiac bypass surgery and during cardiac arrest. However, it is contra-indicated in anuria and uraemia and should be used with caution in renal impairment because it has been associated with hyperkalaemia. There are no reports of its use in the treatment of biguanide-associated lactic acidosis.

Haemodialysis with bicarbonate replacement fluid has been used successfully in the treatment of metformininduced acidosis because it not only corrects the acidosis but also efficiently removes metformin from plasma, preventing further lactate over-production (the clearance of metformin is estimated to be about $68 \mathrm{ml} \cdot \mathrm{min}^{-1}$ ) [9]. However, all our patients were considered to be too haemodynamically unstable to tolerate haemodialysis. In our experience, venovenous haemodiafiltration is better tolerated in such patients because fluid shifts are less precipitate. The correct choice of replacement and dialysate fluids is important as conventional fluids contain lactate as a buffer. If this cannot be metabolised by the liver due to either liver dysfunction or low liver blood flow, the acidaemia may be exacerbated. We therefore used $0.9 \%$ saline as the dialysate and $4 \%$ dextrose $/ 0.45 \%$ saline and sodium bicarbonate $8.4 \%$ as replacement fluids in Case 1, while in Case 2, Ringer's sodium solution was used as both dialysate and replacement fluid. We used high venovenous filter flows to encourage plasma clearance $\left(100 \mathrm{ml} \cdot \mathrm{min}^{-1}\right.$ in Case 1 and $120 \mathrm{ml} \cdot \mathrm{min}^{-1}$ in Case 2). Only one case report was found in the literature of the successful treatment of severe lactic acidosis by haemofiltration [10]. This patient had developed a type A lactic acidosis due to septicaemia and multi-organ failure and was successfully treated with venovenous haemofiltration, using a mixture of $0.9 \%$ saline and $8.4 \%$ sodium bicarbonate (sodium concentration $139-212 \mathrm{mmol}^{-1} \mathrm{l}^{-1}$ ) as replacement fluid and a filter flow rate of $67 \mathrm{ml} \cdot \mathrm{min}^{-1}$.

The poor outcome in Case 1 may be explained by cardiovascular collapse occurring before hospital admission and therefore the relatively late initiation of treatment. The combination of extreme acidosis and sickle cell trait also complicated the case. The persistently decreasing haemoglobin level may have reflected sickling 
of erythrocytes. However, we felt that in view of his overall condition all appropriate measures were taken to address the factors predisposing to sickling.

In all our cases, failure to recognise the severity of their condition led to delays in admission to ICU. These patients became severely acidotic, with $\mathrm{pHs}$ less than 7.0, and hypothermic, presumably due to intense vasodilatation. Severe hypotension occurred in all cases due to low SVR rather than for cardiac reasons. The low SVR was extremely resistant to treatment until the acidosis was treated.

We wish to emphasise that metformin overdose is a serious condition and we recommend early and intensive treatment guided by invasive monitoring. If cardiovascular collapse occurs, it is likely that vasoconstrictors, rather than inotropic agents, will be required. Vigorous attempts should be made to prevent further hypothermia. Venovenous haemodiafiltration using a non-lactate containing replacement fluid may improve the outcome if sodium bicarbonate alone fails to correct blood $\mathrm{pH}$, especially if plasma sodium levels are above $150 \mathrm{mmol}^{-1}$. Suitable replacement fluids include Ringer's sodium solution or a combination of sodium bicarbonate $8.4 \%$ given concurrently with $4 \%$ dextrose $/ 0.45 \%$ saline.

\section{References}

1 Lim HS, Chew SK, Sin FL, Tan YT. Lactic acidosis phenformin overdose. Singapore Medical Journal 1986; 27: 336-40.

2 McLelland J. Recovery from metformin overdose. Diabetic Medicine 1985; 2: 410-11.

3 Gan SC, Barr J, Arieff AI, Pearl RG. Biguanide-associated lactic acidosis. Case report and review of literature. Archives of Internal Medicine 1992; 152: 2333-6.

4 Tymms DJ, Leatherdale BA. Lactic acidosis due to metformin therapy in a low risk patient. Postgraduate Medical Journal 1988; 64: 230-1.

5 Lim PS, Huang CC, Wei JS. Metformin-induced lactic acidosis - report of a case. Journal of the Formosan Medical Association 1992; 91: 374-6.

6 Bailey CJ. Metformin - an update. General Pharmacology 1993; 24: 1299-301.

7 Ritter JM, Doktor HS, Benjamin N. Paradoxical effect of bicarbonate on cytoplasmic pH. Lancet 1990; 335: 1243-6.

8 Stacpoole PW, Harman EM, Curry SH, Baumgartner TG, Misbin RI. Treatment of lactic acidosis with dichloroacetate. New England Journal of Medicine 1983; 309: 390-5.

9 Lalau JD, Westeel PF, Debussche X, et al. Bicarbonate haemodialysis - an adequate treatment for lactic acidosis in diabetics treated by metformin. Intensive Care Medicine 1987; 13: 383-7.

10 Barton IK, Streather CP, Hilton PJ, Bradley RD. Successful treatment of severe lactic acidosis by haemofiltration using a bicarbonate-based replacement fluid. Nephrology Dialysis Transplantation 1991; 6: 368-70. 